\title{
PELAKSANAAN PERATURAN GUBERNUR BALI NOMOR 65 TAHUN 2017 TERHADAP PEKERJA YANG BEKERJA PADA PERUSAHAAN PENJUAL ALAT DAN BAHAN BANGUNAN DI DESA PEKRAMAN PEMOGAN, KECAMATAN DENPASAR SELATAN
}

\author{
Oleh: \\ Dewa Gde Isana Prabhakta Putra \\ Dr. I Wayan wiryawan.,S.H,.M.H. \\ I Made Dedi Priyanto,. S.H,. M.Kn. \\ Bagian Hukum Perdata Fakultas Hukum Universitas Udayana
}

\begin{abstract}
ABSTRAK
Dalam ketenaga kerjaan di Indonesia adanya hal yang perlu di perhatikan dalam kesejahtraan pekerja terutama dalam hal pengupahan. Untuk memperhatikan kesejahtraan setiap pekerja yang ada di Indonesia harus di perhatikan dalam hal pemberian upah agar sesuai dengan kebutuhan yang di perlukan oleh para pekerja untuk memenuhi kebutuhan hidupnya. Dalam hal ini setiap kabupaten/kota telah menentukan batas minimum upah di setiap kabupaten atau biasa di sebut Upah Minimum Kabupaten/Kota. Upah minimum di berbagai kabupaten/kota di Provinsi Bali telah di tentukan dalam Peraturan Gubernur Bali Nomor 65 Tahun 2017 Tentang Upah Minimum Kabupaten/Kota. Jadi karena sudah di tentukan dalam Peraturan Gubernur Bali.

Penelitian ini menggunakan metode penelitian hukum yuridis empiris serta jenis pendekatan yang di gunakan dalam penelitian yaitu jenis pendekatan perundang-undangan, pendekatan fakta, dan pendekatan analisis konsep hukum.

Hasil dari penelitian ini adalah perusahaan alat bahan dan bangunan yang bernama UD. Mega Bayu dan UD. Serati yang bertempat di Desa Pemogan Kecamatan Denpasar Selatan dalam hal pemberian upah kepada para pekerjanya masih memberikan upah di bawah upah minimum yang di telah di tentukan dalam Peraturan Gubernur Bali Nomor 65 Tahun 2017 Tentang Upah Minimum Kabupaten/Kota. Perusahaan yang memberikan upah di bawah upah
\end{abstract}


minimum ini di kerenakan dalam pemberian upah perusahaan ini memberikan upah kepada pekerjanya berdasarkan keuntungan yang di dapat oleh perusahaan tersebut. Pemerintah harus menegaskan dan memberikan informasi kepada perusahaan tentang batas minimum pengupahan sebagaimana di tentukan dalam Peraturan. Agar peraturan ini terlaksana dengan baik dan sesuai dengan mekanisme yang telah di tentukan.

\section{Kata Kunci: upah, Pekerja, Peraturan Gubernur Bali Nomor 65 Tahun 2017}

\section{ABSTRACT}

Welfare of workers need to be considered in employment in Indonesia, especially in terms of wages. Provision of wages for workers in Indonesia must be considered in accordance with the needs of workers to fulfill their living needs. Each district / city has set a minimum wage limit which is usually called the District / City Minimum Wage (UMK). Minimum wages in various districts / cities in the Province of Bali are determined in Bali Governor's Regulation Number 65 of 2017 concerning District / City Minimum Wages. Because the UMK has been determined in each region, each company must provide wages as specified in the regulation.

This research uses juridical empirical legal research methods and uses legislative approach, facts approach, and legal conceptual analysis approach.

Based on this research, can be determined that the wages of workers in the company of tools and building materials with the name UD. Mega Bayu and UD. Serati, who is domiciled in Pemogan Village, South Denpasar Subdistrict, is still under the minimum wage. Companies that provide wages under the minimum wage are based on the profits that have gotten by the company. The government must confirm and provide the information to the company regarding the minimum wage as stipulated in the Bali Governor Regulation Number 65 of 2017 concerning District / City Minimum Wages. So that, this regulation can be able to carried out properly and accord with the mechanism that has been determined

\section{Keywords: Wages, workers, Bali Governor Regulation Number 65 of 2017}




\section{PENDAHULUAN}

\subsection{Latar Belakang}

Sumber daya manusia adalah bagian penting untuk melaksanakan pembangunan nasional, dikarena kualitas dan peran sumber daya manusia yang secara besar yang dalam penentuannya kearah keberhasilan untuk pembangunan nasional. Pembangunan terhadap sumber daya manusia terutama dalam bidang ketenagakerjaan merupakan bagian yang berperan dalam pembangunan sumber daya manusia, dan dalam rangka menjalankan roda pembangunan di negara tercinta Indonesia ini.

Yang dimaksud bekerja yakni usaha dilakukan oleh seseorang untuk mendapatkan penghasilan agar dapat memenuhi semua yang dibutuhan dalam hidupnya ${ }^{1}$. Dan untuk mendapatkan penghasilan tersebut, seseorang akan memerlukan orang lain untuk dapat melakukan interaksi dalam hubungan yang bantu-membantu atau gotong-royong dan saling tukar bantu dalam memberikan segala apa yang telah dimiliki dan mendapatkan segala apa yang diperlukan dari orang lain. Seseorang yang kurang atau tidak memiliki modal atau penghasilan inilah yang memerlukan pekerjaan untuk mendapat penghasilan dalam memenuhi kebutuhan hidupnya. ${ }^{2}$

Dalam Undang-Undang Nomor 13 Tahun 2003. Yang telah menentukan sebagaimana upah yang berikan kepada pekerja harus sesuai dengan tenaga, tingkat kesulitan, dan pertumbuhan ekonomi di wilayah atau daerah itu sebagaiman di atur Dalam Pasal 88

\footnotetext{
${ }^{1}$ Harjono, 2008, Perlindungan Hukum Ketenagakerjaan, PT. Grafindo Persada, Jakarta, h 46

2 Soedarjadi, 2008, Hukum Ketenagakerjaan, Pustaka Yustisia, Bandung, h. 37
} 
Undang-undang Nomor 13 Tahun 2003. Dalam pasal 88 ini menentukan:

1. semua pekerja/buruh berhak mendapatkan penghasilan untuk memenuhi kenghidupan yang layak bagi kemanusiaan.

2. Untuk mendapat penghasilan yang memenuhi kenghidupan yang layak bagi kemanusiaan sebagaimana ditentukan pada ayat (1), pemerintah menetapkan kebijakan pengupahan yang dapat melindungi pekerja/buruh.

3. Kebijakan upah yang melindungi pekerja/buruh sebagaimana ditentukan dalam ayat yakni:

a) upah minimum;

b) upah kerja lembur;

c) upah tidak masuk kerja karena berhalangan;

d) upah izin atau tidak masuk kerja karena melakukan kegiatan lain di luar pekerjaannya;

e) upah karena menjalankan hak waktu istirahat kerjanya;

f) bentuk dan cara pembayaran upah;

g) denda dan potongan upah;

h) hal-hal yang diperhitungkan dengan upah;

i) struktur atau skala dalam pengupahan yang proporsional atau seimbang;

j) upah untuk pembayaran pesangon

k) upah untuk dapat diperhitungan dalam pajak penghasilan.

Dalam pemberian upah yang di maksudkan dengan pengupahan minimum pada pasal 88 ini di jelaskan pada pasal 89 Undang-undang Nomor 13 Tahun 2003 yang menyatakan:

1. Upah minimum sebagaimana ditentukan dalam Pasal 88 ayat (3) huruf a dapat terdiri atas. 
2. upah minimum yang didasarkan pada wilayah provinsi atau kabupaten/kota.

3. upah minimum berdasarkan provinsi atau kabupaten/kota.

4. Upah minimum yang ditentukan dalam ayat (1) ditujukan kepada pencapaian kebutuhan hidup layak.

5. Upah minimum sebagaimana ditentukan didalam ayat (1) ditetapkan oleh Gubernur dengan memperhatikan rekomendasi dari Dewan Pengupahan Provinsi dan/atau Bupati/Walikota.

6. Komponen serta pelaksanaan tahapan dalam pencapaian kebutuhan hidup layak sebagaimana ditentukan dalam ayat (2) diatur dengan Keputusan Menteri.

Dalam undang-undang ketenagakerjaan ini juga setiap pengusaha juga wajib memberikan jaminan kesehatan kepada setiap pekerja yang berkerja dalam perusahan itu dalam Undang-undang Nomor 13 tahun 2003. Yang menentukan tentang jaminan kesehatan kepada tenaga kerja pada pasal 86 yang menyatakan ${ }^{3}$ :

1. Setiap para pekerja atau buruh memiliki hak dalam memperoleh perlindungan atas

a) keselamatan dan kesehatan kerja.

b) moral dan kesusilaan.

c) perlakuan yang sesuai dengan harkat dan martabat manusia serta nilai-nilai agama.

2. Untuk melindungi keselamatan yang diperuntukan pekerja/buruh guna mewujudkan produktivitas kerja yang

3 Sentosa Sembering, 2005, Himpunan Peraturan Perundangan-Undangan Republik Indonesia Tentang Ketenagakerjaan, CV. Nuansa Aulia, Bandung, h 56 
optimal diselenggarakan upaya keselamatan dan kesehatan kerja.

3. Perlindungan sebagaimana dimaksud dalam ayat (1) dan ayat (2) dilaksanakan sesuai dengan peraturan perundangundangan yang berlaku.

Dalam hal perlindungan hukum Undang-Undang RI Nomor 25 Tahun 1997 di jelaskan bahwa perlindungan terhadap tenaga kerja telah di tentukan dalam pasal 98 yakni setiap tenaga kerja berhak atas perlidungan atas keselamatan dan kesehatan tenaga kerja, moral dan kesusilaan, dab perlakuan yang sesuai dengan harkat dan martabat dan manusia dan agama ${ }^{4}$.

Dalam perusahaan juga membuat atau mengadakan sistem keselamatan dan kesehatan para pekerja dalam setiap melakukan perkerjaan yang telah di tentukan pada pasal 87 Undang-Undang Nomor 13 Tahun 2003 Tentang Ketenagakerjaan, yakni5:

(1) Setiap perusahaan wajib untuk menerapkan sistem manajemen keselamatan dan kesehatan kepada kerja yang terintegrasi dengan sistem manajemen perusahaan.

(2) Ketentuan mengenai penerapan sistem manajemen keselamatan dan kesehatan uyuk para pekerkerja sebagaimana ditentukan dalam ayat (1) diatur dalam Peraturan Pemerintah.

Dalam Peraturan Gubernur Bali Tahun 65 Tahun 2017, yang membahas tentang upah minimum regional bali saat ini yang di

4 Muchamad Taufiq dan Zainul Hidayah, 2011, Jurnal: Kajian Hukum Terhadap Perselisihan Hubungan Kerja Secara Sepihak Pada Perusahaan, Jurnal WIGA Vol. 2, Nomor 2, September 2016. H. 9

${ }^{5}$ Lalu Husni, 2000, Hukum ketenagakerjaan Indonesia, Raja Grafindo Persada, Jakarta, h. 37 
tetapkan dan telah tercantum pada peraturan ini adalah upah pokok yang harus di terima oleh tenaga kerja. dalam tenaga kerja tetap maupun tenaga kerja waktu tertentu sebagai mana dimaksud dihitung pendapatan dalam jangka waktu perbulan ${ }^{6}$. Perusahaan yang saya ingin teliti dan saya dapat sebuah kesenjangan terhadap peraturan baik itu peraturan Undang-undang Nomor 13 Tahun 2003, Peraturan Pemerintah Nomor 78 tahun 2015 Tentang Pengupahan dan implementasi dari peraturan yang ditetapkan oleh Peraturan Gubernur Bali Nomor 65 Tahun 2017 Tentang Upah Minimum Kabupaten/Kota. Perusahaan yang saya teliti ini berlokasi di desa parkraman pemogan, kecamatan denpasar selatan, kota denpasar, Bali. Nama tempat yang saya temukan kesenjangan dalam pemberian Upah yang tidak sesuai UMK yakni bernama UD. Mega Bayu dan UD. Serati masing-masing perusahaan tersebut melakukan usaha jaul beli alat dan bahan Bangunan.

\subsection{Tujuan Penelitian}

1. Untuk dapat mengetahui pelaksanaan dalam pemberian upah kepada tenaga kerja yang menerima upah di bawah UMK (Upah Minimum Kabupaten/Kota) yang sesuai dengan perataruran Undang-undang Nomoe 13 Tahun 2003 Tentang Ketenagakerjaan dan sebagaimana minimum upah yang telah di tetapkan dalalm Peraturan Gubernur Bali Nomor 65 Tahun 2017 Tentang Upah Minimum Kabupaten/Kota yang berada Di Desa Pemogan, Kecamatan Denpasar Selatan

\footnotetext{
${ }^{6}$ Ibid, h. 28
} 
2. untuk dapat mengetahui penyebab dari sulitnya suatu perusahaan untuk memberikan upah sesuai dengan upah minimum yang telah di tentukan oleh Peraturan Gubernur Bali Nomor 65 Tahun 2017.

\section{ISI MAKALAH}

\subsection{Metode Penelitian}

Yang dimaksud dalam penelitian adalah cara-cara yang di tempuh untuk memahami objek yang menjadi sasaran penelitian guna mencari dan mendapatkan suatu kebenaran hukum. jenis penelitian yang digunakan dalam penelitian ini adalah penelitian yuridis empiris. Yang di maksud dengan yuridis Empiris ini adalah suatu cara yang dapat ditempuh untuk mendapatkan kebenaran, yaitu dengan cara membandingkan suatu aturan yang ada dengan pelaksanannya atau kenyataan dalam masyarakat (dasollen dan dassein $)^{7}$.

\subsection{Hasil Dan Pembahasan.}

\subsubsection{Implementasi Peraturan Gubernur Bali Nomor 65 Tahun 2017 Tentang Upah Minimum Kabupaten/Kota Terhadap Pekerja Yang Bekerja Pada Perusahaan Penjual Alat Dan Bahan Bangunan Di Desa Pakraman Pemogan, Kecamatan Denpasar Selatan}

Di Provinsi Bali terdapat berbagai macam usaha dagang yang di lakukan di masyarakat. Perusahaan tersebut mempekerjakan pekerja

\footnotetext{
${ }^{7}$ Achmad Ali dan Wawie Herayani, Menjelajahi Kajian Empris Terhadap Hukum, Premedia Groub, Jakarta, H.2
} 
atau karyawan. Dalam hal ini perusahan-perusahan tersebut melaksanakan pengupahan kepada buruh yang dipekerjakan.

Dalam segi pengupahan yang ada Di Kota Denpasar terdapat peraturan yakni Peraturan Gubernur Bali NOmor 65 Tahun 2017 Tentang Upah Minimum Kabupaten/Kota Denpasar. Dalam Peraturan Gubernur Nomor 65 Tahun 2017 Tentang Upah Minimum Kabupaten/Kota Di Denpasar sudah mengatur tentang pelaksanaan pengupahan di kota denpasar dalam hal ini sebagaimana di atur dalam Peraturan Gubernur Nomor 65 Tahun 2017 Tentang Upah Minimum Kabupaten/Kota sebagaimana yang telah ditentukan pasal 2 yaitu Upah Minimum Kabupaten/Kabupaten Kota ditetapkan sebagaimana tercantum dalam lampiran merupakan bagian yang tidak terpisahkan dari Peraturan Gubernur ini dan dalam peraturan gubernur ini telah di tentukan bahwa upah minimum Di Kota Denpasar pada tahun 2018 yakni sebesar Rp. 2.363.000,00 (Dua Juta Tiga Ratus Enam Puluh Tiga Ribu Rupiah). Dalam Peraturan Gubernur ini sudah menentukan upah minimum yang harus di berikan perusahaan kepada buruh atau pegawai yang dipekerjakan.

Dan hal ini juga telah ditentukan dalam Undang-Undang Nomor 13 Tahun 2013 Tentang Ketenagakerjaan juga di tentukan dalam pada pasal 89 yakini "upah minimum yang sebagaimana dimaksud pasal 88 ayat (3) huruf a terdiri atas upah minmum berdasarkan wilayah kabupaten/kota dan upah minimum yang telah ditentukan dalam upah minimum berdasarkan sektor wilayah provinsi atau kabupaten/kota". Dalam pengupahan sebagaimana di tentukan oleh Peraturan Gubernur ini Dan Undang-Undang Nomor 13 Tahun 2013 Tentang ketenagakerjaan sudah ditentukan dalam hal 
pengupahan yang harus di berikan perusahaan kepada pekerja Dalam penelitian ini perusahaan yang menjadi tempat peneliti ini bertempat Di Desa Pakraman Pemogan, Kecamatan Denpasar Selatan. Perusahan ini bernama UD. Mega Bayu Dan UD.

Berdasarkan keterangan dari Bapak Dedi Wiajaya, Ibu Nikmatul Aini, Dan Robi Jayadi pekerja dari U.D. Mega Bayu di ketahui bahwa upah yang mereka terima dari perusahaan U.D. Mega Bayu yakni sebesar Rp 1.300.000,00 (satu juta tiga ratus ribur upiah). Jadi upah yang telah di terima oleh para pekerja masih di bawah Upah Minimum Kabupaten/Kota (UMK). (Wawancara tanggal 12 September 2018).

Dan berdasarkan keterangan dari Bapak Kadek Supena dan Fendi Dianto. Pekerja yang bekerja pada perusahaan U.D. Serati mengatakan bahwa upah yang di berikan oleh perusahaan sebesar Rp 1.900.000,00 (satu juta Sembilan ratus ribu rupiah). Dan menurut hasil wawancara di atas upah yang di berikan perusahaan kepada para pekerja masih di bawah Upah Minimum Kabupaten/Kota (UMK). (Wawancara tanggal 15 September 2018)

Dari hasil wawancara kedua perusahaan dia atas upah yang diterima dari kedua perusahaan tersebut masih memberikan upah di bawah UMK. Maka dalam pelaksanaan Peraturan Gubernur Bali Nomor 65 Tahun 2017 Tentang Upah Minimum Kabupaten/Kota. 


\subsubsection{Faktor-faktor Yang Menyebabkan Perusahaan Tidak Mampu Untuk Memberikan Upah Kepada Pekerja Sesuai Dengan Upah Minimum Kabupaten/Kota Pada Perusahaan Penjual Alat Dan Bahan Bangunan Di Desa Pekraman Pemogan,
Kecamatan Denpasar Selatan.}

Di dalam pemberian upah kepada pekerja pada toko bangunan Di Desa Pakraman Pemogan Kecamatan Denpasar Selatan ini terdapat beberapa toko alat dan bahan bangunan yang masih memberikan upah minimum di bawah upah minimum kabupaten/kota (UMK). Terdapat 2 perusahaan yang menjual alat dan bahan bangunan, perusahaan itu bernama UD. Mega Bayu dan UD. Serati.

Kebijakan upah minimum yang di tentukan Peraturan Gubernur Bali Nomor 65 Tahun 2017 masih belum memihak kepada kepentingan pekerja/buruh. Dalan kenyataan di lapangan masih banayak pekerja yang mendapat upah di bawah standar minimum

Dari uraian di atas ada beberapa faktor yang menentukan perbedaan upah diantaranya adalah Perbedaan dalam tingkat pengalaman kerja, Proporsi dalam pembaian pekerjaan, Jumlah keuntungan yang di dapat perusahaan, Kemampuan pengusaha dalam mempengaruhi harga barang dalam pasar penjulan, Para pekerja dalam pengupahanya sesuai dengan tingkat kesulitan dan resiko keselamatan kerja ${ }^{8}$.

Dalam hasil wawacara dengan pemilik UD. Mega Bayu yang bernama Bapak Satria Wangsa mengatakan bahwa kendala dalam

8 Yunus Shamad, 1995, Hubungan Industrial Di Indonesia, PT. Bina Sumberdaya Manusia, Jakarta, h. 23. 
pemberian upah yang sesuai dengan upah minimum yang di tentukan. Perbedaan tingkat pendidikan yang rendah sehingga dalam pemberian upah yang di terima oleh pekerja sangat minim dan tidak memenuhi syarat pengupahan yang sebagaimana di tentukan dan jumlah keuntungan yang di dapat oleh perusahaan juga mempengaruhi dalam pemberian upah kepada para pekerjanya. (Wawancara tanggal 12 September 2018)

Dalam hasil wawancara dengan Bapak Ida Bagus Perang pemilik dari perusahaan UD. Serati juga mengatakan demikian hanya saja dia mengatakan bahwa keuntungan dari biaya barang yang di produksi dan telah terjual oleh perusahaan juga mempengaruhi dalam pemberian upah yang di berikan kepada para pekerjanya. (Wawancara tanggal 15 September 2018)

Dalam hal ini perusahaan yang tidak mampu memberi upah sebagaimana di tentukan Peraturan Gubernur Bali Nomor 65 Tahun 2017 yang disebabkan oleh ketidak mampuan perusahaan dalam memberikan Upah yang sesuai UMK kepada para pekerjanya harus mengikuti sistematis yang telah di tentukan. Sebagaimana yang telah di tentukan pada pasal 6 dalam perturan PERGUB Bali ini. Agar di beri penangguhan kepada perusahaan tersebut sebagaimana di atur dalam Undang-undang Nomor 13 Tahun 2003 yang telah ditentukan pasal 90 yang menentukan bagi perusahaan yang tidak mampu membayar upah minimum dapat di lakukan penangguhan. Untuk sanksi perusahaan sudah di tentukan dalam dalam pasal 185 dalam Undang-undang Nomor 13 Tahun 2003 barang siapa yang melanggar pasal 90 tentang ketenagakerjaan akan di kanakan pdana penjara paling singkat 1 tahun penjara dan paling lama 4 tahun penjaradan 
dikenakan denda $\mathrm{Rp}$ 100.000.000,00 dan paling banyak Rp 400.000.000,00. Dan dalam hal ini sudah terjadi tindak pidana yang tela dilakukan oleh pemilik perusahaan..

\section{PENUTUP}

\subsection{Kesimpulan}

Dalam hal ini dapat disimpulkan sebagai berikut:

1. Bahwa dalam pelaksanaan Peraturan Gubernur Bali nomor 65 Tahun 2017 untuk para pekerja yang bekerja pada perusahaan penjual alat bahan dan bangunan di Desa Pakraman Pemogan, Kecamatan Denpasar Selatan tidak terlaksana dengan maksimal sebagaimana yang telah di tentukan.

2. Faktor-faktor yang menyebabkan perusahaan tersebut sulit untuk memberikan upah pekerja sesuai dengan Upah Minimum Kabupaten/Kota (UMK) Di Desa Pakraman Pemogan Kecamatan Denpasar Selatan yakni karena dalam pemberian upah kepada pekerjanya, perusahaan itu tergantung pada keuntungan yang di dapatkan, Sementara keuntungan yang di dapat perusahaan masih rendah atau sedikit untuk mampu memberikan upah yang sesuai di tentukan dalam Peraturan

\subsection{Saran}

Dalam melakukan penelitian ini ada beberapa saran uang dapat di berikan yakini:

1. Perlunya di laksanakannya Peraturan Gubernur Bali Nomor 65 Tahun 2017 Tentang Pengupahan kabupaten/Kota oleh pemerintah. Dan dapat di terima oleh para pekerja dan perusahaan. Agar peraturan ini dapat di laksanakan dan dapat 
memberi manfaat hukum baik itu untuk para pekerja maupun untuk perusahaan itu sendiri.

2. Dalam hal in dapat di sarankan agar pemerintah melakukan sosialisasi dan penyebaran informasi tentang upah minimum yang telah di tentukan dalam peraturan gubernur Bali ini. Dan memudahkan perusahaan dalam meminta penangguhan Kepada Dinas Ketenagaakerjaan sebagaimana dia di tentukan pasal 6 di dalam Peraturan Gubernur Bali Nomor 65 Tahun 2017 dan dapat memberikan informasi yang jelas tentang upah minimum dan membantu pekerja dalam menuntut hak upah dari perusahaan dengan cara menjelaskan bagaimana cara melakukan upaya hukum untuk menuntut hak pengupahan kepada perusahaan. Dan agar perusahaan mengetahui cara meminta penangguhan kepada pemerintah dalam pengupahan sesuai dengan mekanisme yang telah di tentukan 


\section{DAFTAR PUSTAKA}

\section{Buku-Buku}

Achmad Ali dan Wiwie Heryani 2012, Menjelajahi Kajian Empriris Terhadap Hukum, Premedia Groub, Jakarta

Harjono, 2008, Perlindungan Hukum Ketenagakerjaan, PT. Grafindo Persada, Jakarta.

Lalu Husni, 2000, Hukum ketenagakerjaan Indonesia, Raja Grafindo Persada, Jakarta.

Sentosa Sembering, 2005, Himpunan Peraturan PerundanganUndangan Republik Indonesia Tentang Ketenagakerjaan, CV. Nuansa Aulia, Bandung.

Soedarjadi, 2008, Hukum Ketenagakerjaan, Pustaka Yustisia, Bandung

Yunus Shamad, 1995, Hubungan Industrial Di Indonesia, PT. Bina Sumberdaya Manusia, Jakarta.

\section{Jurnal}

Muchamad Taufiq dan Zainul Hidayah, 2011, Jurnal: Kajian Hukum Terhadap Perselisihan Hubungan Kerja Secara Sepihak Pada Perusahaan, Jurnal WIGA Vol. 2, Nomor 2, September 2016.

\section{Peraturan Perundang-undang}

Undang - Undang No 13 Tahun 2003 Tentang Ketenagakerjaan 
Undang-Undang Nomor 2 Tahun 2004 Tentang Penyelesaian Perselisihan Hubungan Industrial.

Peraturan Pemerintah Nomor 78 Tahun 2015 Tentang Pengupahan

Nama,tahun, judul jurnal, jurnal apa? Volume,nomor, tahun posting

Peraturan Gubernur Bali Nomor 65 Tahun 2017 Tentang Upah Minimum Kabupaten/Kota 